\title{
On Expansion and Features of Word-formation between English and Chinese New Words*
}

\author{
Rongmei Yu \\ NanChang Normal University, Jiangxi, China
}

\begin{abstract}
The most important tool for expressing thoughts and communicating information among people--language has emerged some main changes as the development of modern science and technology. Thousands of new words have emerged in both English and Chinese. Their emergence reflects the new things; new thoughts and new ideas appeared in the fast developing society. This paper starts with the history of the study of word-formation, analyzes the main methods of word-formation of new words of English and Chinese, then compares their features of word-formation. Although English and Chinese belong to the different language system, their main methods of word-formation are the same. The reason leading to the distinction is the difference of each other's culture, history and tradition. The biggest difference between them is: English is phonogram, but Chinese lays stress on matching the meaning. This also makes them show remarkable differences in absorbing and assimilating the loanwords. Using abundant examples and materials, the paper expounds the similarities and differences between them in different aspects, According to the study of these comparisons, it will do favor for us to find out English and Chinese new words' features and their trend of development.
\end{abstract}

Index Terms—English new words, Chinese new words, word-formation, features of word-formation, expansion

\section{INTRODUCTION}

With the development of modern science and technology, every field, from politics, economy, culture to the daily life, great changes have taken place. As the most important tool for expressing thoughts and exchanging information among people, language has emerged great changes as well. Thousands of new words have emerged in both English and Chinese. They are the most obvious symbols of changes happened in the social life. New words were created to refer to those new things, reflecting the rapid development and change of our daily life. The faster the society advanced, the more the new words appeared. In 1990s, there are almost 2168 new words appeared in modern Chinese (Xinhua New Word Dictionary). So the changes happened in the society brought out the changes of languages. Every language has emerged changes in all fields: pronunciation, lexical, grammar and pragmatics, in which words have emerged the biggest change. Vocabulary is a dynamic and open system, and the most active element in language. Though other elements of a language, such as pronunciation and grammar have also changed, vocabulary is the most evident one. The appearances of so many new words prove it.

Vocabulary is a dynamic and open system, and the most active and important element in language. With the development of modern science and technology as well as social, economic and political changes, thousands of new words have emerged in both English and Chinese. According to the survey taken by Gozzi, the writer of New Words and Changing American Culture (1990), "In the 12.000 new words of modern English, 45\% of that is from technology, 24\% comes from social changes, as well as $11 \%$ is from political and economic change. Meanwhile, in 1980s, there are almost 700 new words appeared per year in modern Chinese". (Zhu YongKai, Lin Lun Lun 1999, (02) P.17).

Word-formation, in its restricted sense, refers to the process of word variations signaling lexical relationships. It can be further subclassified into the compositional type and the derivational type. The rules of word-formation are concluded from the specific language from the scientific aspect. Foreign students can understand and memorize Chinese better through learning these rules, so can the Chinese students when they are learning foreign languages. The Indian linguist Panini (4th. Century B.C.) stated the word-formation of Sanskrit elaborately in his works, which influenced Europe deeply. But a long time since then, the study of word-formation had not developed well. In the early $20^{\text {th }}$ Century, linguistics developed in full scale except word-formation. Synchronic and diachronic theories were greatly used at that time. In 1957, after Chomsky pressed Syntactic Structure, many famous linguists changed their analysis methods. Structuralists were not interested in word-formation, for what they concerned was the unit that's inferior to a word. Transformationists were also not keen on it, because they attached importance to the unit that's prior to a word (phrases and sentences); they believed that sentences were formed by morphemes not words. Till the 80s, linguists began to study word-formation from different perspectives. Some applied the phonetic analysis method, some used diachronic theory and others utilized the semantic analysis.

As we discussed above, word-formation studies the means of word construction of a certain language. So it should be

${ }^{*}$ This paper is funded by 11531 project of Nanchang Normal University 
lexical and productive, and should reflect the problems of phoneme, meaning, syntax and rhetoric. Before we deal with word-formation proper, we will first explain some of the terminologies to be used in the study of word-formation. Morpheme is the smallest unit of language in terms of relationship between expression and content, a unit that cannot be divided into further smaller units without destroying or drastically altering the meaning, whether it is lexical or grammatical. Morphemes can be subclassified into different types; here I would like to introduce two main types: root and affix. A root is the base form of a word that cannot further be analyzed without total loss of identity. That is to say, it is that part of the word left when all the affixes are removed. In the word "multiculturalism", after the removal of "inter-"“-al" "-ism", what is left is the root "culture". All words contain a root morpheme. An affix is the collective term for the type of formative that can be used only when added to another morpheme (the root or stem). Affixes are limited in number in a language, and are generally classified into two subtypes, namely, prefix and suffix, depending on their position with reference to the root or stem of the word. For example, "mono-" "semi-" "-hood" "-ment", etc. The rules of word-formation define the scope and methods whereby speakers of a language may create new words; for instance, the -able word-formation rules says, "-able is to be added to verbs to form an adjective meaning 'fit to be', or to nouns to form an adjective with the sense showing the quality of." And one of the noun compound formations is noun plus noun. However any rule of word-formation is of limited productivity in the sense that not all the words that result from the application of the rules are acceptable.

The paper first put on the history of the study of word-formation and explain some of the necessarily-to-known terminologies, then discuss the new word formation between English and Chinese respectively, next compare their features in terms of similarities and differences, and draw a conclusion that contrastive analysis of the expansion of English and Chinese new words and their features of word-formation would do favor for us to find out their trend of development.

\section{COMPARISON IN THE EXPANSION OF ENGLISH AND CHINESE NEW WORDS}

Though English and Chinese belong to different language family, the expansion of their new word is the same. The differences lie on the specific forms of their own.

\section{A. Word Formation}

Traditional word-formation is always the main expansion for creating new words. There are various word formations. Here the four major means will be discussed in detail; they are affixation, composition, analogy and shortening.

1. Affixation is the morphological process whereby an affix is attached to a root or stem. It is very productive and was once the most important word-formation of language. In modern English there appears several new affixes, such as -gate, -nik, -speak, etc. “-speak” was first found in Longman Dictionary of Contemporary English (1987\&1995), which means language, version and statement. It is always put behind name, team, organization and profession. For example, netspeak (网络语言), bureauspeak(官僚语言), businessspeak (商业术语). The prefix “multi- ” means “a lot, various”, multiculturalism（多元文化）, multiskilling（多功能化）, multitasking（计算机多重任务处理）; the suffix “-head” means "someone who is not popular or passionate on something”, digital-head (电脑迷), net-head (网虫), tech-head

（技术迷）. In Chinese new words, there are also some created by affixation.For example, “一族”，追星族，上班族， SOHO族, 月光族, 丁克族等。“一迷”, 歌迷, 影迷, 书迷等。“网—”, 网吧, 网恋, 网民, 等。

2. Composition is the mean that compounds two or more words into a new one in some order. The term compound covers a wide range of different relations between lexical words. On the whole, it refers to those words that consist of more than one lexical morpheme, or the way to join two separate words to produce a single form. In compounds, the two lexical morphemes can be of different word classes. Usually the right-hand member not only determines the category of the whole compound, but it also determines the major part of the sense of the compound. In this sense, the right member serves as the head. Many of English new words were created in this way. Such as, gay marriage（同性婚 姻）, opinion leader（與论导向人）, rapid reaction force（快速反应部队）,etc. If used properly, these compounding words can make sentences simple and well understood. It is the same situation in Chinese language. There are also some new words created by composition. For example, 多媒体教学, 减肥保健饮料, 搬家公司, 快餐文化等。

3. An analogy takes some similar word as the pattern, carries on association analogy in the semantics, replaces some morpheme, and imitates its correspondence or the similar new word. For example, "telecast" is analogized by "newscast"; "heliport" is analogized by "airport"; "moonscape" is analogized by "landscape", Be same with English, in Chinese analogy words also emerge one after another incessantly. There is a word“空中小姐”, then “导游小姐”, “礼 仪小姐”, “柜台小姐”and “亚洲小姐” emerge.

4. Shortening is another important word formation in modern English. There are four types of them, clipping, such as chemotherapy - chemo; initialism, such as automated checkout machine-ACM; acronym, such as small office/home office-SOHO; and the last one blending, such as "chunnel" is blended with "channel" and "tunnel"; "videophone" is blended with "video" and "telephone"; "medicare" is blended with "medical" and "care", and "psywar" is blended with "psychological" and "warfare". The Chinese characters can show the meaning strongly, many Chinese characters can increase, reduce, open, and spell. This characteristic has decided Chinese has extremely productive ability to form shortening words. There are two types of Chinese shortening words. The first type is to extract the crucial morpheme of 
the original word or phrase to compose the new word. For example，摆脱贫困一脱贫; 武装警察一武警. The other one is numeral shortening. For example, 三个代表, 八荣八耻, 等.

\section{B. Borrowing Words}

With the development of modern technology and the international communication, the width and depth of inter-language and inter-culture communication has achieved the unprecedented degree. There is continuous melting among different culture, so is language. Language is the most important means of communication. No language is ever self-sufficient. With the development of international exchanges, language contact has become not only inevitable, but also more frequent. Generally speaking, all languages contain a certain amount of foreign linguistic elements. Once absorbed, these foreign linguistic elements become part of the borrowing language. This is an important way for a language to enrich and replenish itself.

English in its development has managed to widen her vocabulary by borrowing words from other languages. Greek, Latin, French, Spanish, Arabic and other languages have all played an active role in this process. Throughout its history, the English language has adopted a vast number of words from various sources. In modern English, most borrowing words are from Latin language family by meaning translation and phonetic loan. For example, cancer(癌, 毒瘤), subpoena（传票）from Latin, epilepsy(癫㾋症),atom(原子) from Greek, fashion(时装), delicatessen（熟食店）from Germany, ciao (再见) from Italian, karaoke (卡拉OK), judo(柔道) from Japanese, and also tai chi (太极拳), kong $f u$ (功夫) from Chinese.

In the contact with other national language cultures, Chinese also borrows many external words and expressions from other languages. The phonetic loans are divided into four types:

1. A complete phonetic loan, which is a foreign word being translated into Chinese entirely according to its sound, e.g. hysteria(歇斯底里), EL.Nino（厄尔尼诺）, clone（克隆）, copy（拷贝）,sofa(沙发), disco(的士高).email(伊 妹儿);

2. A sound-meaning half-half translation, e.g. Internet（因特网）, derby blue（德比蓝）, Cambridge（剑桥）

As we can see from the examples, words of such kind are translated partially according to the sound, and partially according to the meaning of the original word.

3. A phonetic loans with a generic term added, e.g. sauna（桑拿浴）, AIDS（艾滋病）, waltz（华尔兹舞）

There are a lot of loans of this kind in Chinese. The characteristic of such words is that a generic term is added at the end of each word. This is perhaps because without the generic term to indicate its category, the word might be misunderstood to refer to some other things. Chinese people like to use words that indicate meanings.

4. A sound-meaning translation, e.g. hippies（嬉皮士）, vitamin（维他命）, neon（氛）

A sound-meaning translation is a word that is translated both according to its sound and according to its meaning. For example, in the word '铋' the '必' part is the sound for the first syllable of 'Bismuth', and the '金' part indicates that the thing '铋' is a metal.

\section{New Meaning in Old Words}

It is the method that entrusts new meaning to the words, which exist originally to constitute the new words. The social development, the change of values, the sex difference and the language change and so on all have the possibility to cause the evolution of word meaning. The old English word obtaining the new meaning mainly displays in:

1. The broadening of meaning. Broadening is a process to extend or elevate the meaning from its originally specific sense to a relatively general one. For example, "divorce" originally meant "to put an end to a marriage by law", but now it also means "to put an end to the relationship of family members". "companion" originally meant "a person with whom you share bread", but now it also means "a person who accompanies you". "task" originally meant "tax imposed", but now it also means "a piece of work".

2. The narrowing of meaning. Contrary to broadening, the original meaning of a word can be narrowed or restricted to a specific sense. For example, "net" originally meant all the nets, but now it particularly refers to the Internet. "liquid" originally meant liquid, but now it particularly refers to an alcoholic beverage made by distillation.

3. The promotion of meaning. For example, "awesome" meant "full of awe" before, and after a period it meant "dreadful", but now it promoted to mean "great and marvelous", which is popular in the late 20th Century.

The expansion of this method in Chinese language is almost the same to the English language. There are three types: the reference of meaning. Such as, “下课”, “充电”; the broadening of meaning. Such as, “触电”, “遥控”, “电灯泡”; the promotion of meaning. Such as, “跳槽”, “老板”.

Those word-formation discussed above are the main type in English and Chinese new words. Through the comparison, we can draw a conclusion that the similarities are more than differences between the two languages of word-formation.

\section{Contrastive Analysis of the Features of Word-Formation Between English And Chinese New Words}

Though there is a big gap between English and Chinese culture, their certain features are the same. Language reflects 
culture, so there are both similarities and differences between English and Chinese new word formation.

\section{A. The Similarities}

\section{The Analogizing of the Word-formation Process.}

The analogy has become the most important word-formation in modern English and Chinese language. Because it conforms to people's thought custom, operates easily, and has broad scope to construct word. In present open society, both British and China societies, as the carrier of popular culture, the news publication and the popular work attracts the reader to pursue the novel things. They often imitate these existing words to concoct new words sedulously, which reflect the new change and also show "the popular colors". Therefore it was fashionable for a time. Thus it causes massive emergent of new words in both English and Chinese language. "According to the survey, the analogizing words have the proportion of 10\% in English and Chinese respectively". (Zhou Xu Qiang, 2001,(5) P .19).

\section{The Reference of the Language Becomes Shorter and Shorter.}

It is the reflection of this quick and efficient society that requests the economy and accuracy. In order to adapt this request, people often use those words that have few language marks, short line and the informative and communicative expressions. The quantity of English shortening words is huge, only the initial words account for $25 \%$ of the total quantity. Chinese shortening words although is inferior to English in the quantity, with the swift development of science and technology it will certainly be able to increase rapidly.

\section{The Internal Structure Tends to Be Phrase.}

The new words of English and Chinese are not only double-syllable, but also three-syllable, four-syllable, even five-syllable, which take on the multi-syllable tendency. This phenomenon is especially conspicuous in the compounding new words of them. The development of the society and the continuous emergence of new things, new thoughts and new concepts lead to the gradually attentive thoughts of people. In order to reflect those new changes, the internal structure of English and Chinese new words have to become more and more complicated. This is an apparently common feature of English and Chinese new word-formation in the new times.

\section{The Pragmatics Process Presents Oral.}

The new words and expressions are mostly created and popular in the young people who like to pursue fashion. These new words and expressions most exist in orally; and extremely vivid. For example, in Chinese, “闪”means "leave or go", which is more oral and fashionable.

\section{Acceptant Process Is Unfamiliar.}

The new words and expressions appear too quickly and fashionably, but they are too brief to express the meaning clearly. However there are some words whose spelling and form is out of standard, so the new words are a little bit unfamiliar, which make the majority person feel strange, and they have difficulty in accepting them.

However, these two languages belong to different language system; there are still many differences in the features of word-formation between their new words.

\section{B. The Differences}

\section{The Absorptive and Assimilative Function Is Different.}

The absorptive and assimilative function of English language is very strong, as long as the word or expression is useful, it will accept. Moreover, it has very strong plasticity and high flexibility in the word construction. When the borrowing words enter English, the pronunciation and form will be assimilated by English language soon. But the assimilative function of Chinese borrowing words is far inferior to English. When it is needed to use the borrowing new words, meaning translation is often used, little transliteration. Chinese language always tries to reform the borrowing words with native language custom and word construction. Just because the English borrowing words occupy about $80 \%$ in the complete vocabulary (Li Changbao, 2001:92), English vocabulary has a laudatory name as "the cosmopolitan vocabulary". Compared with English, the percentage of borrowing words in Chinese is much smaller.

\section{Writing Performance System Is Different.}

The English language attaches importance to shape, and can reveal pronunciation from its writing. Its new words and expressions take the letter or the word as the fundamental component, its shape, sound and meaning establish separately, and it controls the semantics by the grammar; the Chinese language emphases the meaning, its new words and expressions take the Chinese character as the fundamental component, its shape, sound and meaning integrate, and it controls the grammar by the semantics. Take the new shortening words for example, in English CW can present "continuous wave", "cold welding", "chemical warfare"; but in Chinese a shortening word can only stand for one meaning. Such as, 公关 (公共关系)

\section{The Morpheme Development Tendency Has Differences.}

The morpheme is the smallest meaning unit in the language that may divide into free morpheme and bounding morpheme, and can also divide into meaningful morpheme and meaningless morpheme. Generally speaking, the free morpheme is meaningful, while bounding morpheme is meaningless. In the process of creating new English words, no matter which word-formation is used, the phenomenon that meaningless syllable becomes meaningful would never happen. But it is a completely different case in Chinese language. There is the phenomenon in Chinese. For example, “的” is meaningless originally and is a bounding morpheme. But in the phrase “打的”, it does have the meaning of 
“taxi”. Similarly, there are many phrases in which “的” has meaning. Such as, “面的”“摩的”“板的”等.

\section{CONCLUSION}

Vocabulary is an important element in language. With the development and change in society, there must be more and more new words appeared and served in daily communication. Language development trend and rule could be found by contrastive analysis of the expansion of English and Chinese new words and their features of word-formation. Totally speaking, traditional word-formations are still the most important means to create new words. They use the old structure to indicate completely new meanings. English and Chinese are from entirely different language systems, because the differences of each culture and tradition, their features of word-formation are different in some aspects. Along with the further communication and mutual influence between the two cultures, these two languages must have greater development.

\section{REFERENCES}

[1] Chen Guang Lei. (2001). Chinese Lexical theory. ShangHai: Xuelin Publishing House, 2001.8

[2] Holley, Shawn. (2000). New English words and new meaning. Translated by Wu Qian and Luo Yan. Beijing: Tsuinghua University Press, 2000.

[3] Hu Zhuang Lin. (2015). Linguistics. A Course Book (second edition).Beijing: Peking University Press.2015.07

[4] Li Chang Bao. (2001). A Comparative Study of Loanwords in English and Chinese. Beijing: Foreign Language Teaching, 2001,(5):92-96

[5] Longman. (1995). Longman Dictionary of Contemporary English (New Edition). Hong Kong: The Commercial Press \& Longman, 1995.

[6] Luo Ying (1995). The Impact of English on Chinese Lexis. Hebei: Journal of North China University of Technology, 1995.(12):57--62

[7] P.H. Matthews (2000). Morphology (Second Edition). Beijing: Foreign Language Teaching and Research Press \& Cambridge University Press, 2000.8

[8] Stuart C. Poole (2010). An Introduction to Linguistics. Beijing: Foreign Language Teaching and Research Press.

[9] Zhou Xu Qiang. (2001). The Common Features of Word Formation in Contemporary English and Chinese. Beijing: Foreign Language and Foreign Language Teaching, 2001, (5):17-19.

[10] Zhu YongKai, Lin Lun Lun. (1999). The Characteristics and Producing Ways of Neologisms in the Past Twenty Years. Use of Language and Literature, (2)17-18 Chendu: Sichuan Institute of Foreign Languages Press, 040325

Rongmei Yu was born in JiangXi province China in 1964. She received her Bachelor's degree in English Language and Literature from JiangXi Normal University, China in 1989.

She is currently a professor in Nan Chang Normal University, JiangXi, China. Her research interests include Intercultural Communication and English Teaching.

Prof. Yu is a member of JiangXi Translation Association and the teacher of Nan Chang Normal University. 